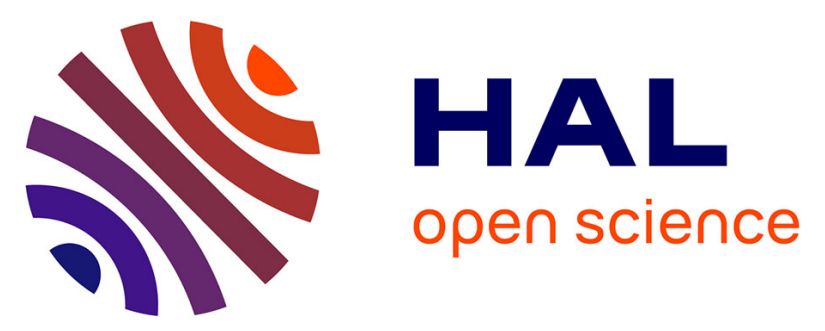

\title{
Improving the Study of Social Representations through Word Associations: Validation of Semantic Contextualization
}

\author{
Anthony Piermatteo, Jean-Louis Tavani, Grégory Lo Monaco
}

\section{To cite this version:}

Anthony Piermatteo, Jean-Louis Tavani, Grégory Lo Monaco. Improving the Study of Social Representations through Word Associations: Validation of Semantic Contextualization. Field Methods, 2018, 30 (4), pp.329 - 344. 10.1177/1525822x18781766 . hal-01911870

\author{
HAL Id: hal-01911870 \\ https://hal.science/hal-01911870
}

Submitted on 4 Nov 2018

HAL is a multi-disciplinary open access archive for the deposit and dissemination of scientific research documents, whether they are published or not. The documents may come from teaching and research institutions in France or abroad, or from public or private research centers.
L'archive ouverte pluridisciplinaire HAL, est destinée au dépôt et à la diffusion de documents scientifiques de niveau recherche, publiés ou non, émanant des établissements d'enseignement et de recherche français ou étrangers, des laboratoires publics ou privés. 


\section{Associations: Validation of Semantic Contextualization}

\section{Anthony Piermattéo', Jean-Louis Tavani², and Grégory Lo Monaco ${ }^{3}$}

\section{Abstract}

To grasp how individuals and groups perceive social objects of their environment, word association tasks enable the cognitions associated with a given object to be collected. However, the lack of information regarding the meaning of these responses implies interpretation and subjectivity in their analysis. To reduce this subjectivity, this research aims to validate semantic contextualization (SC), a procedure that allows participants to explain the link they establish between their response and the object under study. In an experimental study, we asked 94 undergraduate students to

\footnotetext{
1 Unité de recherche OceS, Université Catholique de Lille, Lille, France

2 LAPPS EA 4386, Université Paris 8 Vincennes Saint-Denis, Saint-Denis, France

${ }^{3}$ LPS EA 849, La maison de la recherche, Centre ALLSH, Aix-Marseille Université, Aix-en-Provence, France
}

\section{Corresponding Author:}

Anthony Piermattéo, Unité de recherche OceS, Université Catholique de Lille, 60 Boulevard Vauban, CS 40109, 59016 Lille Cedex, France.

Email: anthony.piermatteo@univ-catholille.fr 
categorize the results of word association tasks, having available or not the responses resulting from the SC task. We observed that SC improved categorization at different levels such as perception of the difficulty of the task, agreement between participants, uncertainty, and homogeneity of the categorization. These results lead us to consider this method a useful addition to word association tasks.

\section{Introduction}

How can we study how people perceive the world and the objects of their social environment? Since the initial formulation of the theory of social representations (SRs), many methodological contributions in this field have focused on this question (Abric 2003; Doise et al. 1993; Flament and Rouquette 2003; Lo Monaco et al. 2017). As SRs are "systems of opinions, knowledge, and beliefs particular to a culture, a social category, or a group with regard to objects in the social environment" (Rateau et al. 2011:478), many of these methodologies aim to gather these shared and socially elaborated cognitions related to social objects. Among these, word association tasks constitute one of the main methods for collecting the content of SRs (Dany et al. 2015; Lo Monaco et al. 2017). Furthermore, word association data are used in linguistics and psycholinguistic research and in many humanities and social sciences (De Deyne and Storms 2015; Moliner and Lo Monaco 2017).

However, this method, which consists of asking people about the words that come to their mind in reference to a given stimulus word that is related to the object under study, is not flawless. In fact, the polysemy that frequently characterizes the gathered words limits the ability to understand the meaning they have for the respondents. Consequently, the study of these responses is subject to an interpretation that can vary from one researcher to another. To deal with this issue, this contribution focuses on the validation of the semantic contextualization (SC), an additional procedure in which participants are asked to write a sentence expressing the meaning they wished to assign to their associations in relation to the stimulus word. Finally, if methodological issues such as the one we address in this contribution impact a disciplinary field (i.e., in our case, social psychology), it is relevant for other disciplines such as linguistics and psycholinguistic as well as anthropology, sociology, and so forth. 


\section{SRs and Word Associations Tasks}

This contribution falls within the methodological field of the theory of SRs. On the basis of the initial work of Moscovici (1961, 2008), this theory focuses on the way people collectively form and share representations of objects from their social environment (e.g., material and immaterial objects such as the environment, new concepts and technologies). In other words, SRs are sets of opinions, knowledge, and beliefs that result from a social construction of reality. They are the result of specific processes influenced by values, ideologies, social characteristics, and experiences that lead groups to a common perception of the world around them (Moscovici 2008). As such, SRs constitute a guide to interactions withor regarding - social objects such as communications (Markova 2000; Moscovici 1993, 2008), position-taking (Clémence 2001; Doise et al. 1993), and practices (Abric 1994). In the words of Moscovici (1963:251), they can be considered collective elaborations "of a social object by the community for the purpose of behaving and communicating." In a more concrete way, as a product, SRs are a set of cognitions that can take the form of words and expressions and can be studied as such. This set refers to the content of the SR.

Many methods have been proposed to collect these contents, such as interviews, focus groups, and questionnaires integrating word association tasks (see Wagner et al. 1999). The latter method, one of the most used (Lo Monaco et al. 2017; Moliner and Lo Monaco 2017), is, according to Abric (1994:66), "a fundamental technique for collecting the content of social representations." The large number of studies dealing with various objects of SR whose content has been revealed by verbal associations is in line with this position (for recent works, see Dany et al. 2015; Jung and Pawlowski 2015; Mouret et al. 2013; Piermattéo et al. 2014). As mentioned above, this method provides access to the contents of SRs by asking people about the words or expressions that come to mind in reference to the object under study. Moreover, word association tasks can be easily adapted according to the aims and constraints of researchers. It is thus possible to (1) ask participants to produce one, two, three, or $x$ words; (2) ask for a specific type of response: adjectives, verbs, nouns, and feelings; or (3) use a substitution procedure in which participants are asked to answer as a member of a wider social group in which they are included (Guimelli and Deschamps 2000). Despite all these possible variations, when used in the context of SRs studies, word association tasks usually consist of asking for three to five responses without requesting a specific nature of the associated words 
(Dany et al. 2015; Flament and Rouquette 2003). It should be noted, however, that responses collected through a verbal association task only represent a possible manifestation of SR, which remains a structure of sociocognitive knowledge.

Besides their adjustability, word association tasks are simple and easy to understand by participants and can be carried out quickly (see Lo Monaco et al. 2017, for a review of the advantages and disadvantages of this method). This latter characteristic enables researchers to add other tasks or procedures to word association questionnaires, which can help specify the collected data.

\section{Additional Tasks and Procedures}

Many additions to word association tasks have been proposed to improve their effectiveness. In this perspective, Abric (1994) added a second phase to the associative task in which participants had to associate new words on the basis of their previous associations with the stimulus word. Another addition consists of asking participants to specify the valence of each associated response on a Likert-type scale (for a recent example, see Piermattéo et al. 2014). Similarly, de Rosa (1993) proposed the "associative network" procedure, in which participants are asked to draw an associative map by connecting with lines their responses between each other and/or with the stimulus word. Along with this first task, participants have to (1) specify the valence of their associations with the symbols "+," "-," or " 0 " (i.e., neutral); (2) specify the order in which these associations came to their mind; and (3) rank them by importance (for a recent example, see Penz and Sinkovics 2013). As for the associative network procedure, one of the most common additions to word association tasks consists of asking participants to rank the words they associated by order of importance. This addition, called the "hierarchical evocation method," is frequently used in research conducted within the framework of the structural approach to SRs (Abric 1976; Lo Monaco et al. 2017).

Thus, in addition to the many qualities of the word association task, its adaptability and the additional tasks proposed in the literature make it a major tool for the study of SRs. Nevertheless, this method is not flawless.

\section{Categorization: A Limit of Word Association Tasks}

Recent reflections on the limitations of the methods of studying SRs (Lo Monaco et al. 2017; Piermattéo et al. 2014) have underlined the issue 
related to the categorization of data resulting from word association tasks. Categorization is a major step in the treatment of word association tasks, which aims to reduce the collected data to a small number of categories. For example, in such a task, if 100 participants are asked to produce five responses, 500 word associations will be collected. Of these, while some words can be unique, others can have multiple occurrences, appear in different forms (e.g., teacher, teachers), or have a close meaning (e.g., teacher, professor, pedagogue). Although the various forms of the same word can easily be regrouped (i.e., a lemmatization procedure, see Di Giacomo 1980), gathering the word associations characterized by a semantic proximity requires correctly determining the meaning of the responses for the participants. However, the polysemy of some word associations, or the lack of information regarding why they have been associated, leave room for interpretation and subjectivity in the categorization process (Bonnec et al. 2002). Consequently, different categories can be created from one researcher to another and a representational content may be highlighted that does not adequately fit with the SR of the studied sample.

This limitation is an important issue as categorization constitutes the basis of a wide variety of other methods of studying SRs as well as data analyses related to word association tasks, such as Q-sort methodologies (Abric 2003; Lo Monaco et al. 2012), correspondence factor analysis and other multidimensional analyses (Doise et al. 1993; Lo Monaco et al. 2012; Piermattéo et al. 2014), prototypical analysis (Danermark et al. 2014; Dany et al. 2015), or structural diagnosis methods (for a synthesis, see Lo Monaco et al. 2017).

\section{The SC Task}

Considering the stakes associated with the issue of categorization, only a few methods have been proposed in the literature, and neither of these appears to be used systematically or consensually. Di Giacomo (1980), following the recommendations of Rosenberg and Jones (1972), avoided regrouping responses that do not "obviously" have the same meaning. However, while this method limits the risks of inaccurate categorization, it directly affects the frequency of categories in which some responses could have been placed if their meaning had been properly identified. Danermark et al. (2014:496) achieved categorization through a process involving at least two researchers who "constantly discussed and consulted with each other to determine the most suitable category for each item." Such a procedure could indeed limit the subjectivity of the categorization process. 
However, although collective, it still relies on interpretation, and debate or agreement does not guarantee that researchers correctly infer the accurate meaning of associated responses. The issue of agreement between coders to avoid misuse has been the subject of several publications (Feng 2014, 2015; Lombard et al. 2004; Oleinik et al. 2014).

Another method called "SC" was proposed by Piermattéo et al. (2014). It is inspired by the work of Guimelli (1996, 2003) and consists of asking participants to formulate, after the word association task, a sentence for each associated word. Participants are required to specify for each sentence the link expressing the meaning that they wished to assign to their association in relation to the stimulus word. By directly asking participants about the meaning of their responses instead of inferring it, Piermattéo et al. (2014) hypothesized that the resulting categorization would be more objective. However, the authors reported no information regarding the effectiveness of this method, as the aim of their research was not to validate it. Thus, as noted by Lo Monaco et al. (2017), while SC seems to constitute a potential response to the issue of categorization, no work has been conducted to assess its effectiveness.

The aim of this contribution is to conduct such a validation. An experimental study was designed consisting of a task in which participants had to categorize the data from a previous study while having available (or not) the responses related to the SC task. In line with Piermattéo et al. (2014), we hypothesized that having available information resulting from the SC would reduce the ambiguity of the meaning of the word associations to categorize and improve the objectivity of the categorization.

\section{Method}

\section{Population}

The sample was composed of 94 undergraduate psychology students from a French university (84 women, $M_{\text {age }}=20.23$, standard deviation [SD] $=$ 2.20). The study was part of a course on the methods of studying SRs during which the categorization of word association tasks had been the subject of an extended presentation. However, we intentionally avoided presenting the problems related to this methodology and addressed in the framework of this study. In this course, participants were asked to form pairs to participate in an exercise on categorization. 


\section{Material and Procedure}

In the categorization task, each pair of participants received a booklet composed of three sections. The first presented the instructions related to the task. According to the course on the categorization of word association tasks, these instructions were focused on: (1) the creation of categories as general classes which can encompasses the responses that appears to refer to the same meaning or idea or (2) the distribution of the responses among these categories. The second consisted of a table containing the word associations to categorize. The table was composed of three to four columns depending on the experimental conditions. The first column presented the words resulting from a previous study that had been conducted on another sample of 122 undergraduate psychology students. In this preliminary study, half the participants in the sample were asked about their SR of drugs, while the other half were asked about their SR of higher education.

The study consisted of a questionnaire composed of a word association task followed by an SC task. More precisely, participants were asked to associate the four words or phrases that come to mind when we say "drugs" (or "higher education," depending on the condition). We chose these two objects to assess the relevance of participants' categorization, as they have been studied several times on similar samples and have been the object of relatively consistent categorizations in the literature (Echabe et al. 1992; Guimelli and Rateau 2003; Lo Monaco et al. 2008). The number of types (i.e., the number of different words) varied from 80 for the object "drugs" to 95 for the object "higher education" and all the raw answers $(N=136$ for the object "drugs" and $N=189$ for "higher education") were sorted alphabetically and provided as a list to participants for the categorization task.

Depending on the experimental conditions, a second column presented, for each word, the sentence resulting from the SC task of the preliminary study. The last two columns of the table were available for all the participants and devoted to the categorization. The first one was to be filled with the category chosen for each word by participants. The second one was devoted to the evaluation of the agreement within pairs of participants. More precisely, for each categorized word, we asked participants to fill the cell with a number ranging from 1 (strong disagreement) to 4 (strong agreement). In line with the procedure used by Danermark et al. (2014), participants were instructed to discuss the categorization of each word and then to report their level of agreement regarding their choice. 
The last section of the booklet was a questionnaire composed of two parts. The first part was intended to be filled by the two participants from each pair together. We instructed them to specify all the categories they had created. The second part of the questionnaire was intended to be filled individually by each member of the pairs of participants. It was composed of six 7-point Likert-type scales ranging from -3 (not at all) to 3 (totally). Two questions assessed the perception of the general difficulty of the task (e.g., "I found it difficult to categorize the words"). Two other individual questions assessed the perception of the general agreement with the other member of the pair (e.g., "Concerning the categorization, I often agreed with the person I carried out the exercise with"). The two remaining questions assessed the perception of the general difficulty of inferring the meaning of the words to categorize (e.g., "Some of the words had several meanings, which made their categorization difficult").

\section{Results}

We submitted subjective evaluations of the task by participants and pairs of participants, as well as the results of the categorization itself to 2 (SR object: drugs vs. higher education) $\times 2$ (availability of the responses resulting from the SC task: availability vs. nonavailability) factorial analyses of variance (ANOVAs). For each of these analyses, a significant main effect of the availability of the responses resulting from the SC task was expected, indicating that, when available, this information improves the categorization and allows a better within-pairs agreement and a perception of the task as less complicated.

\section{Subjective Evaluation}

Individual measurements. ANOVAs conducted on individual measurements revealed a significant interaction effect related to the perception of the general difficulty of inferring the meaning of the words to categorize, $F(1,90)=4.69, p<.05, \eta_{\mathrm{p}}^{2}=.05$. Concerning this item, although we did not observe a main effect of the availability of the SC, post hoc analyses with Tukey's honestly significant difference (HSD) test revealed a significant effect of the SC for the SR object "drugs" $(p<.05)$. Thus, for this object, participants reported greater difficulty in categorizing words with several meanings when the responses from the SC task were not available $(M=1.75, \mathrm{SD}=1.24)$ than when they were $(M=0.63, \mathrm{SD}=1.71)$. However, this difference was not significant for the SR object "higher education" $(p=.98)$. Concerning the other items (i.e., general difficulty 
of the task and general agreement with the other member of the pair), ANOVAs did not reveal a main effect of the availability of SC nor an interaction effect with the SR object.

Within-pairs agreement. The modalities of response related to within-pairs agreement were split into two groups: frequencies of responses to modalities 1 and 2 were computed to provide a score of low agreement, while frequencies of responses to modalities 3 and 4 were computed to give a score of high agreement. ANOVAs performed on these two scores revealed a significant main effect of the availability of SC for the high agreement score, $F(1,43)=3.96, p<.05, \eta_{\mathrm{p}}^{2}=.08$. The analysis showed that participants reported more responses indicating a high level of agreement (modalities 3 and 4) when SC was available. More precisely, this score was higher when SC was available $(M=114.86, \mathrm{SD}=22.61)$ than when it was $\operatorname{not}(M=109.84, \mathrm{SD}=27.04)$.

\section{Impact of SC on Categorization}

Categorical level. On average, each pair of participants produced 10.81 categories $(\mathrm{SD}=2.52)$. We hypothesized that the availability of the SC, by increasing the objectivity of categorization, would limit the variability in the number of categories among pairs of participants. Thus, the absolute difference between the number of categories created by each pair of participants and the mean number of categories created by all pairs of participants depending on the experimental conditions was submitted to an ANOVA. The main effect of the availability of the SC was only marginal, $F(1,43)=3.38, p=.07$. Although not significantly different, the means indicated a greater variability in the number of categories created when the $\mathrm{SC}$ was not available $(M=1.70, \mathrm{SD}=1.79)$ than when it was $(M=1.09$, $\mathrm{SD}=0.85)$. Moreover, the interaction effect was significant, $F(1,43)=$ $4.91, p<.05, \eta_{\mathrm{p}}^{2}=.10$, and Tukey's HSD post hoc test revealed a significant effect of SC for the SR object "higher education" $(p<.05)$, but not for "drugs" $(p=.99)$. Thus, for the SR object "higher education," the variability in the number of categories created was greater when the SC was not available $(\mathrm{M}=2.66, \mathrm{SD}=2.12)$ than when it was $(M=1.10, \mathrm{SD}=0.70)$.

\section{Indexes Related to Categorization}

To assess the impact of the availability of responses resulting from the SC, we computed three indexes on the basis of the categories attributed to each 
Table I. Means, Standard Deviations, and Comparisons Related to the Main Effect of the Availability of the Responses Resulting from the Semantic Contextualization (SC) on Uncertainty, Uniqueness, and Divergence.

\begin{tabular}{|c|c|c|c|}
\hline $\begin{array}{l}\text { Categorization } \\
\text { indexes }\end{array}$ & Availability of SC & Nonavailability of SC & $F$ \\
\hline Uncertainty & $4.09(9.98)$ & $6.05(13.18)$ & $\begin{array}{l}F(I, 646)=6.46 \\
p<.01, \eta_{\mathrm{D}}^{2}=.0 \mathrm{I}\end{array}$ \\
\hline Uniqueness & $23.10(17.40)$ & 32.25 (22.09) & $\begin{array}{l}F(I, 646)=32.22 \\
p<.001, \eta_{\mathrm{D}}^{2}=.05\end{array}$ \\
\hline Divergence & $40.50(19.39)$ & $48.19(21.44)$ & $\begin{array}{l}F(I, 646)=22.26 \\
\quad p<.001, \eta_{\mathrm{D}}^{2}=.03\end{array}$ \\
\hline
\end{tabular}

Note: Standard deviations are in parentheses.

word by pairs of participants and submitted them to factorial ANOVAs (see Table 1). The first index aimed to assess the proportion of uncertainty. For each word to categorize, it was necessary to establish the relationship between the number of pairs of participants who categorized it as "miscellaneous" (i.e., a category chosen when no category fits the word or when its meaning is too uncertain to categorize it) and the total number of pairs of participants belonging to the experimental condition. The second index aimed to assess the proportion of uniqueness. For each word to categorize, it was necessary to establish the relationship between the number of "unique" categories (i.e., a category not similar to any of the other categories attributed by the other pairs of participants) and the total number of pairs of participants belonging to the experimental condition. The last index aimed to assess divergence. For each word to categorize, it was necessary to establish the relationship between the number of different categories attributed and the total number of pairs of participants belonging to the experimental condition. All these indexes were multiplied by 100 to create percentages of uncertainty, uniqueness, and divergence.

Uncertainty. ANOVAs conducted on the three indexes revealed a main effect of the availability of the SC. Concerning the uncertainty index, the mean percentage of categorization as miscellaneous (i.e., the fact of not being able to categorize the word) was higher when the SC was not available $(M=6.05, \mathrm{SD}=13.18)$ than when it was $(M=4.09, \mathrm{SD}=9.98), F(1,646)$ $=6.46, p<.01, \eta_{\mathrm{p}}^{2}=.01$. The interaction effect was also significant, $F(1,646)=6.19, p<.01, \eta_{\mathrm{p}}^{2}=.01$. Tukey's HSD post hoc test indicated 
that the impact of SC was significant for the SR object "drugs" $(p<.01)$, but not for "higher education" $(p=.99)$. More precisely, for the SR object "drugs," uncertainty was higher when the SC was not available $(M=9.51$, $\mathrm{SD}=16.68)$ than when it was $(M=4.90, \mathrm{SD}=11.50)$.

Uniqueness. The main effect of the availability of the SC regarding uniqueness indicated that the mean percentage of uniqueness was higher when the $\mathrm{SC}$ was not available $(M=32.25, \mathrm{SD}=22.09)$ than when it was $(M=23.10, \mathrm{SD}=17.40), F(1,646)=32.22, p<.001, \eta_{\mathrm{p}}^{2}=.05$. The analysis also revealed a significant interaction effect, $F(1,646)=4.96$, $p<.05, \eta_{\mathrm{p}}^{2}=.01$. According to Tukey's HSD post hoc test, the impact of SC was significant for the SR object "higher education" $(p<.001)$, but not for "drugs" $(p=.11)$. Thus, for the SR object "higher education," uniqueness was higher when the SC was not available $(M=38.34$, $\mathrm{SD}=24.34)$ than when it was $(M=26.36, \mathrm{SD}=18.29)$.

Divergence. Concerning divergence, the main effect of the availability of the $\mathrm{SC}$ indicated that the mean percentage of divergence was higher when the SC was not available $(M=48.19, \mathrm{SD}=21.44)$ than when it was $(M=40.50, \mathrm{SD}=19.39), F(1,646)=22.26, p<.001, \eta_{\mathrm{p}}^{2}=.03$. For this index, the interaction effect was not significant.

\section{Discussion}

The results of this study are in line with our hypothesis regarding the ability of the SC task to improve the objectivity of categorization. Subjective evaluations indicate that $\mathrm{SC}$ enables a better understanding of the meaning of the words to categorize and leads to better within-pairs agreement regarding this categorization. In the same way, the results related to the categorization itself show that $\mathrm{SC}$ limits the loss of information resulting from the placing of responses into a miscellaneous category. This technique also limits the appearance of unique categories, which are the consequence of the variable interpretation of the meaning of responses from one pair of participants to another. Finally, we also observed that using SC leads to improved homogeneity (i.e., less divergence) among the categories created by participants. However, for most of these results, the effects were differentiated according to the SR object presented to participants.

This effect of the SR object variable can be explained by the specificity of the data related to each of the two objects used in this study. In fact, each SR is a specific social construction whose content can vary at different levels (see 
Flament and Rouquette 2003). Thus, the ambiguity characterizing some of the responses can vary in frequency (i.e., some objects could have more ambiguous responses than others) or in nature from one object to another. For instance, concerning the object "higher education," the word "work" appeared 28 times in the data as it was cited by more than one participant during the preliminary study that aimed to collect responses for the categorization task. However, the sentences resulting from SC indicated that for 22 participants, work refers to the fact that higher education requires one to work hard, while for others it refers to the fact that higher education prepares students for their future job (the French equivalent of the word work is polysemous and can refer to work as well as job). Thus, regarding higher education, ambiguity stems from the polysemous nature of some of the word associations. However, for the object drugs, ambiguity appears to be more linked to the specificity of some of the responses than to their polysemy. For instance, words like "dathura" or "crocodile" refer to specific types of drugs, sometimes with slang terms (e.g., crocodile or Krokodil is the street name of desomorphine, a derivative of morphine).

For each of these cases, SC allowed participants to understand better the data' meaning and to adopt a more appropriate categorization. Nevertheless, as shown by these two examples, the data related to every SR object are susceptible to present significant variations in their number of polysemous and specific responses. These variations could therefore account for the principal and simple effects of the variable "SR object" across our results and explain why SC improves categorization at different levels depending on the object. In the same way, the variations in the nature of the distribution of the responses can also be taken into account and more precisely, the specific entropy that characterizes the responses related to each SR object. However, the two objects in this study are characterized by a similarly weak entropy, which indicates a more organized and shared knowledge and may affect positively the reliability of the categorization as, in such a case, responses should be characterized by fewer variations in their meaning (see Flament and Rouquette 2003; Moliner and Lo Monaco 2017). Moreover, we did not observe the detrimental effect of the SC variable. Thus, although SC does not systematically improve categorization at every level depending on the object under study, its use is unlikely to affect this task in a negative way.

Another limitation comes from the sample used in our study, which consisted of students, whereas word associations are generally categorized by researchers. However, the students in our sample received extended training in the methods of studying SRs. Moreover, if the categorization by experienced researchers could differ from that of 
students on some levels, it seems unlikely that they would have a better guess of ambiguous and polysemous words. Indeed, uncertainty related to the lack of information characterizing the word associations is likely to be similar, whatever the level of expertise of the people who are doing the categorizing.

However, SC is an additional to the traditional word association task and may therefore have a cognitive cost for participants. For example, for the same question in an online survey, the use of open questions resulted in more nonanswers than the use of check boxes (Couper et al. 2001). So the question of the cost of this extra step must be studied in future empirical research to determine whether the benefits for the data analysis are greater than the costs for the participants.

Thus, SC appears to allow a more objective categorization of collected data, especially considering specific or polysemous responses. But all the responses provided by individuals are not necessarily characterized by such a nature and may rather be more collocational (Nielsen and Ingwersen 1999). In the perspective of SRs studies, such responses are generally not highly informative for the researcher, as this theory considers that individuals and groups give meaning to reality they cope with. However, SC may ensure that such responses are effectively collocational and not characterized by an unexpected deeper meaning for individuals. In addition, SR studies, as well as other fields such as linguistics, are often interested in the quantification of the strength of theses co-occurrences (see Flament and Rouquette [2003] or Mollin [2009] in the field of linguistics). In this perspective, the additional information provided by SC may allow us to confirm the collocational nature of the responses and thus improve the reliability of their quantification. Moreover, as this task is designed to be used in the early stages of the study of a given SR, it also gives access to additional data. In fact, the sentences provided by participants can be submitted to content analyses, thus benefiting from an alternative approach to the studied object. In this way, Piermattéo et al. (2014) conducted a lexicometric analysis of the data resulting from the $\mathrm{SC}$ and showed significant variations in the discourse of participants, depending on the manipulated contexts of collection. However, such an additional step, as it requests individuals to reconsider their responses, may lead to them to modify their initial meaning. Further research is thus needed to assess the impact of SC on participants' responses. Still the additional data offered by SC, along with the results of this study, lead us to consider this method a useful addition to word association tasks. 


\section{Declaration of Conflicting Interests}

The author(s) declared no potential conflicts of interest with respect to the research, authorship, and/or publication of this article.

\section{Funding}

The author(s) received no financial support for the research, authorship, and/or publication of this article.

\section{References}

Abric, J.-C. 1976. Jeux, conflits et représentations sociales. Doctoral diss., Université de Provence, Aix-en-Provence, France.

Abric, J.-C. 1994. Pratiques sociales et représentations. Paris: Presses Universitaires de France.

Abric, J.-C. 2003. Méthodes d'étude des représentations sociales. RamonvilleSaint-Agne, France: Erès.

Bonnec, Y., N. Roussiau, and P. Vergès. 2002. Categorical and prototypical analysis: A study on the quality-process in hospital institutions. European Review of Applied Psychology 52:213-20.

Clémence, A. 2001. Social positioning and social representations. In Representations of the social, eds. K. Deaux and G. Philogène, 83-95. Oxford: Blackwell.

Couper, M. P., M. W. Traugott, and M. J. Lamias. 2001. Web survey design and administration. Public Opinion Quarterly 65:230-53.

Danermark, B., U. Englund, P. Germundsson, and P. Ratinaud. 2014. French and Swedish teachers' social representations of social workers. European Journal of Social Work 17:491-507.

Dany, L., I. Urdapilleta, and G. Lo Monaco. 2015. Free associations and social representations: Some reflections on rank-frequency and importance-frequency methods. Quality \& Quantity 49:489-507.

De Deyne, S., and G. Storms. 2015. Word associations. In The Oxford handbook of the word, ed. J. R. Taylor, 466-80. Oxford: Oxford University Press.

de Rosa, A. S. 1993. The associative network. A new technique for evaluating projective and evaluative components of social representations. EAESP General Meeting, September 16-19, Lisbon, Portugal.

Di Giacomo, J. P. 1980. Intergroup alliances and rejections within a protest movement (analysis of the social representations). European Journal of Social Psychology 10:329-44.

Doise, W., A. Clémence, and F. Lorenzi-Cioldi. 1993. The quantitative analysis of social representations. Hemel Hempstead, UK: Harvester Wheatsheaf. 
Echabe, A. E., E. F. Guede, C. S. Guillen, and J. F. V. Garate. 1992. Social representations of drugs, causal judgment and social perception. European Journal of Social Psychology 22:73-84.

Feng, G. C. 2014. Intercoder reliability indices: Disuse, misuse, and abuse. Quality \& Quantity 48:1803-15.

Feng, G. C. 2015. Mistakes and how to avoid mistakes in using intercoder reliability indices. Methodology 11:13-22.

Flament, C., and M.-L. Rouquette. 2003. Anatomie des idées ordinaires. Comment étudier les représentations sociales. Paris: Armand Colin.

Guimelli, C. 1996. Valence et structure des représentations sociales. Bulletin de Psychologie 49:58-72.

Guimelli, C. 2003. Le modèle des schèmes cognitifs de base (SCB). Méthode et applications. In Méthodes d'étude des représentations sociales, ed. J.-C. Abric, 119-46. Ramonville-Saint-Agne, France: Erès.

Guimelli, C., and J.-C. Deschamps. 2000. Effets de contexte sur la production d'associations verbales. Le cas de la représentation sociale des Gitans. Les Cahiers Internationaux de Psychologie Sociale 47:44-54.

Guimelli, C., and P. Rateau. 2003. Mise en évidence de la structure et du contenu d'une représentation sociale à partir du modèle des SCB comme unique outil d'analyse. Un exemple à propos de la représentation des études. Nouvelle Revue de Psychologie Sociale 3:158-68.

Jung, Y., and S. D. Pawlowski. 2015. The meaning of virtual entrepreneurship in social virtual worlds. Telematics and Informatics 32:193-203.

Lombard, M., J. Snyder-Duch, and C. C. Bracken. 2004. A call for standardization in content analysis reliability. Human Communication Research 30:434-37.

Lo Monaco, G., F. Lheureux, and S. Halimi-Falkowicz. 2008. Test of context independence (TCI) and structure of social representations. Swiss Journal of Psychology 67:119-23.

Lo Monaco, G., A. Piermattéo, C. Guimelli, and J. C. Abric. 2012. Social representations, correspondence factor analysis and characterization questionnaire: A methodological contribution. Spanish Journal of Psychology 15:1233-43.

Lo, Monaco, G., A. Piermatteo, P. Rateau, and J. L. Tavani. 2017. Methods for studying the structure of social representations: A critical review and agenda for future research. Journal for the Theory of Social Behaviour 47:306-31.

Markova, I. 2000. Amédée or how to get rid of it: Social representations from a dialogical perspective. Culture \& Psychology 6:419-60.

Moliner, P., and G. Lo Monaco. 2017. Méthodes d'association verbale pour les sciences humaines et sociales. Grenoble, France: Presses Universitaires de Grenoble. 
Mollin, S. 2009. Combining corpus linguistic and psychological data on word cooccurrences: Corpus collocates versus word associations. Corpus Linguistics and Linguistic Theory 5:175-200.

Moscovici, S. 1961. La psychanalyse, son image et son public. Paris: Presses Universitaires de France.

Moscovici, S. 1963. Attitudes and opinions. Annual Review of Psychology 14: 231-60.

Moscovici, S. 1993. Introductory address. Papers on Social Representations 2:1-11.

Moscovici, S. 2008. Psychoanalysis, its image and its public. Cambridge: Polity Press.

Mouret, M., G. Lo Monaco, I. Urdapilleta, and W. V. Parr. 2013. Social representations of wine and culture: A comparison between France and New Zealand. Food Quality and Preference 30:102-7.

Nielsen, M. L., and P. Ingwersen. 1999. The word association methodology: A gateway to work-task based retrieval. Proceedings of the Final Mira Conference on Information Retrieval Evaluation. https://ewic.bcs.org/content/ConWebDoc/ 4269:17-27 (accessed June 13, 2018).

Oleinik, A., I. Popova, S. Kirdina, and T. Shatalova. 2014. On the choice of measures of reliability and validity in the content-analysis of texts. Quality \& Quantity 48:2703-18.

Penz, E., and R. R. Sinkovics. 2013. Triangulating consumers' perceptions of payment systems by using social representations theory: A multi-method approach. Journal of Consumer Behavior 12:293-306.

Piermattéo, A., G. Lo Monaco, L. Moreau, F. Girandola, and J.-L. Tavani. 2014. Context variations and pluri-methodological issues concerning the expression of a social representation: The example of the Gypsy community. Spanish Journal of Psychology 17:1-12.

Rateau, P., P. Moliner, C. Guimelli, and J.-C. Abric. 2011. Social representation theory. In Handbook of theories of social psychology, eds. P. A. M. Van Lange, A. W. Kruglanski, and E. T. Higgins, 477-87. Thousand Oaks, CA: Sage.

Rosenberg, S., and R. Jones. 1972. A method for investigating and representing a person's implicit theory of personality: Theodore Dreiser's view of people. Journal of Personality and Social Psychology 22:372-86.

Wagner, W., G. Duveen, R. Farr, S. Jovchelovitch, F. Lorenzi-Cioldi, I. Markova, and D. Rose. 1999. Theory and method of social representations. Asian Journal of Social Psychology 2:95-125. 